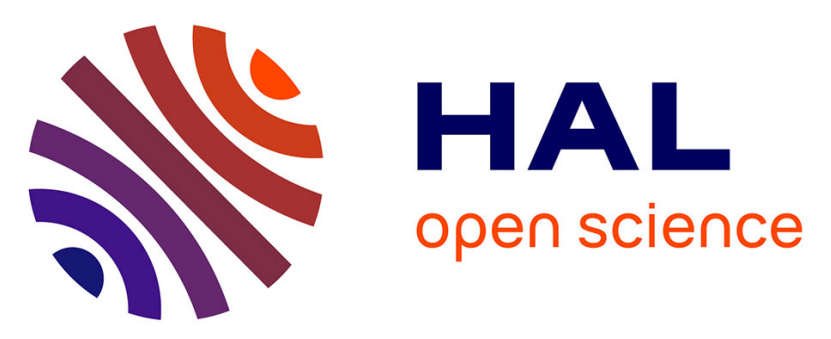

\title{
Modeling of a synchronous reluctance machine accounting for space harmonics in view of torque ripple minimization
}

\author{
Tahar Hamiti, Thierry Lubin, Lotfi Baghli, Abderrezak Rezzoug
}

\section{- To cite this version:}

Tahar Hamiti, Thierry Lubin, Lotfi Baghli, Abderrezak Rezzoug. Modeling of a synchronous reluctance machine accounting for space harmonics in view of torque ripple minimization. Mathematics and Computers in Simulation, 2010, 81, pp.354-366. 10.1016/j.matcom.2010.07.024 . hal-00558540

\author{
HAL Id: hal-00558540 \\ https://hal.science/hal-00558540
}

Submitted on 1 May 2015

HAL is a multi-disciplinary open access archive for the deposit and dissemination of scientific research documents, whether they are published or not. The documents may come from teaching and research institutions in France or abroad, or from public or private research centers.
L'archive ouverte pluridisciplinaire HAL, est destinée au dépôt et à la diffusion de documents scientifiques de niveau recherche, publiés ou non, émanant des établissements d'enseignement et de recherche français ou étrangers, des laboratoires publics ou privés. 


\title{
Modeling of a synchronous reluctance machine accounting for space harmonics in view of torque ripple minimization.
}

\author{
Tahar Hamiti*, Thierry Lubin, Lotfi Baghli and Abderrezak Rezzoug \\ Groupe de Recharche en Electrotechnique et Electronique de Nancy \\ GREEN, CNRS-UMR 7037, Université Henri Poincaré, BP 239 \\ 54506 Vandoeuvre-lès-Nancy Cedex, France \\ Tahar.Hamiti@green.uhp-nancy.fr.
}

\begin{abstract}
The paper deals with modeling of Synchronous Reluctance Motor (SynRM) accounting for all phenomena responsible for torque ripple. Based on winding function approach, the proposed model consists in computing self and mutual inductances considering no sinusoidal distribution of stator windings, slotting effect and no sinusoidal reluctance variation caused by the rotor saliency. Then, optimal current waveforms are determined for each rotor position by a second order equation solving in order to reduce torque ripple. Theses currents are used within a vector control scheme. Satisfactory agreement between simulation and experimental results is obtained.
\end{abstract}

Key words: Synchronous reluctance motor; Winding function; Torque ripple; Optimal currents

\section{Introduction}

SynRM exhibits serious advantages to be used in variable speed drives and servomechanisms, its manufacturing cost, ruggedness and synchronism with power supply frequency can constitute a good challenge [1]. However, the rotor saliency being the origin of electromagnetic torque production is also responsible for torque ripple. This last produces mechanical vibrations and acoustic noise especially when the motor operates at low speeds.

Reference [6] gives an overview of torque ripple minimisation techniques of permanent magnet ac motors, the authors have pointed on a major class of control-based techniques. Among theses techniques, two interesting strategies are presented respectively in [3] and [10]. The first consists on optimal currents injection determined by finite element method and the second is based on a load torque observer and on line torque ripple compensation. However, there are few works in the literature on torque ripple minimization of SynRM neither by current harmonics injection nor by direct on line compensation.

An accurate self- and mutual inductances calculation is necessary to improve the accuracy analysis of the SynRM. Because of rotor saliency and stator windings distribution, the self- and mutual inductances of a SynRM are no sinusoidal [2]. The electromagnetic torque produced by this machine presents a pulsating component in addition to the dc component when it is fed by sinusoidal currents. The rotor position dependence of electromagnetic torque and machine inductances can be evaluated by a variety of methods including analytical method, finite element analysis $[8,14]$ or winding function approach $[11,12,13]$. Finite element method gives accurate results. However, this method is time consuming especially for the simulation of a controlled machine fed by a PWM inverter. In winding function approach, the inductances of the machine are calculated by an integral expression representing the placement of winding turns along the air-gap periphery [12].

\footnotetext{
${ }^{\text {th }}$ Corresponding author
} 


\section{Calculation of inductances using winding function approach}

\subsection{Description of the machine}

The cross-section of a cut-outs rotor SynRM is shown in figure 1. The rotor presents a simple and robust structure. The stator is the same as an induction motor and has single layer, concentric-3 phases distributed winding with $N e$ slots. It is assumed in winding function analysis that the iron of the rotor and stator has infinite permeability and magnetic saturation is not considered.

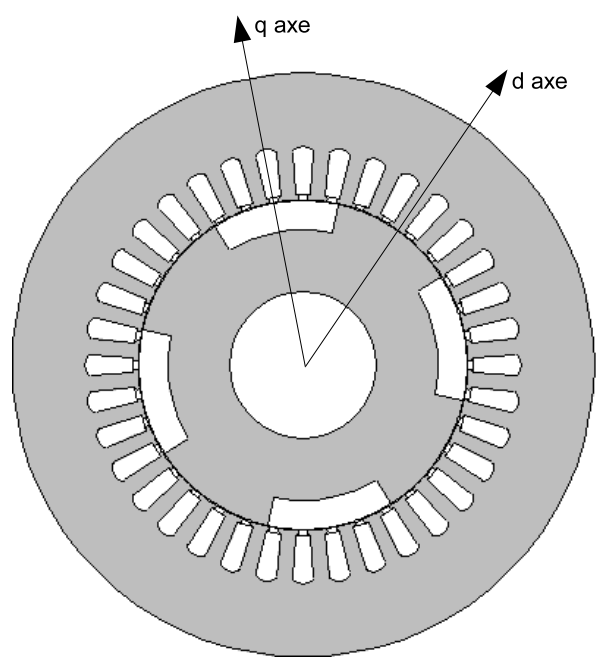

Figure 1: Cross-section of a cut-outs rotor SynRM.

\subsection{Magnetic field in the air gap}

The magnetic field in the air gap is defined as [7]:

$$
H(\alpha-\theta)=\frac{\left(N_{a}(\alpha) \cdot i_{a}(\theta)+N_{b}(\alpha) \cdot i_{b}(\theta)+N_{c}(\alpha) \cdot i_{c}(\theta)\right)}{e(\alpha-\theta)}
$$

where $\theta$ is the angular position of the rotor (electrical angle) with respect to the $a$ winding reference, $\alpha$ is a particular position along the stator inner surface.

The term $N_{i}(\alpha)$ with $i=a, b, c$, represents in effect the magnetomotive force distribution along the air-gap for a unit current flowing the winding $i$. The winding function of the phase $a$ for the studied SynRM is shown in figure 2 where $N$ represents the number of turns in series per phase. The winding function of the phase $b$ and phase $c$ are similar to that of phase $a$ but are displaced by $120^{\circ}$ and $240^{\circ}$ (electrical degrees) respectively.

The air-gap function $e(\alpha-\theta)$ is computed by modeling the flux paths through the air-gap regions using straight lines and circular arc segments. The flux paths due to the rotor saliency are shown in figure $3 \mathrm{a}$ and the corresponding length of the flux lines is given by:

$$
E_{r}(\alpha-\theta)=e_{1}+\frac{R\left(\frac{\pi}{2}-|\alpha-\theta|\right)\left(\sin |\alpha-\theta|-\sin \left(\frac{\beta}{2}\right)\right)}{\cos (\alpha-\theta)} .
$$

where $R, \beta$ and $e 1$ are defined in table 1 . by:

The flux paths due to the stator slots are shown in figure $3 \mathrm{~b}$ and the corresponding length of the flux lines is given

$$
E_{s}(\alpha)=\left\{\begin{array}{cl}
\frac{\pi}{2} R \alpha & 0 \leq R \alpha \leq h_{0} \\
\frac{\pi}{2} R \alpha+\gamma\left(R_{S} \alpha-h_{0}\right) & h_{0} \leq R \alpha \leq \frac{b_{0}}{2}
\end{array}\right.
$$


with:

$$
\gamma=\frac{\pi}{2}-\arctan \left(\frac{h_{1}}{\frac{\left(b_{1}-b_{0}\right)}{2}}\right)
$$

The slot dimensions are $h_{0}=0.9 \mathrm{~mm}, h_{1}=0.4 \mathrm{~mm}, b_{0}=2.5 \mathrm{~mm}$ and $b_{1}=4.3 \mathrm{~mm}$. The total slot depth is $13.6 \mathrm{~mm}$. The total air-gap function is then:

$$
e(\alpha-\theta)=E_{s}(\alpha)+E_{r}(\alpha-\theta)
$$

its representation is shown in figure 4

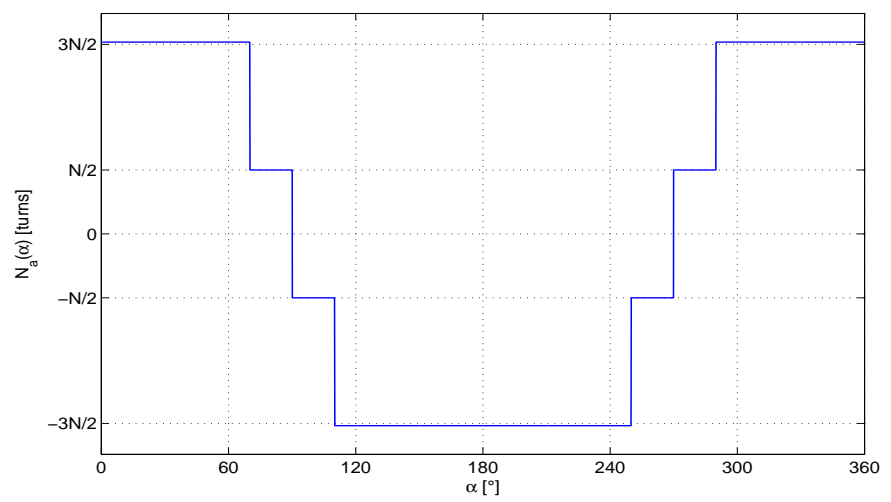

Figure 2: Winding function of the phase $a$

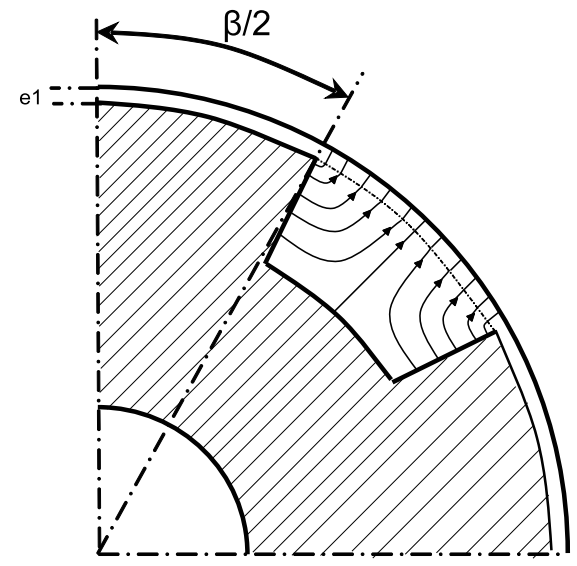

(a) Flux lines distribution due to the rotor saliency

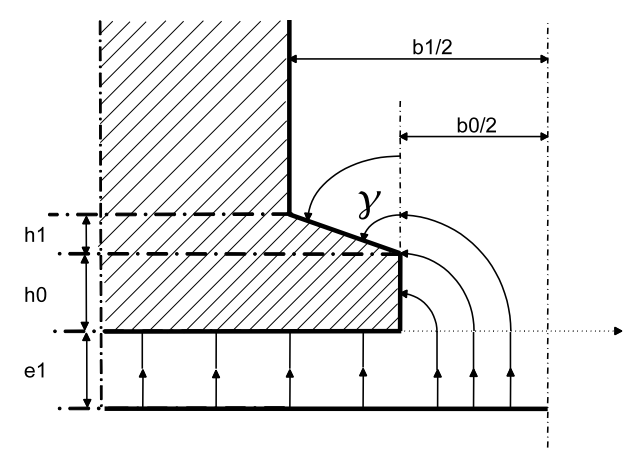

(b) Flux lines distribution due to the stator slots

Figure 3: Flux lines distribution

\subsection{Inductances computation}

In linear conditions, the magnetic energy stored in the airgap, with respect to rotor position, is:

$$
W(\theta)=\frac{\mu_{0}}{2} \iiint_{v} H^{2} d v .
$$




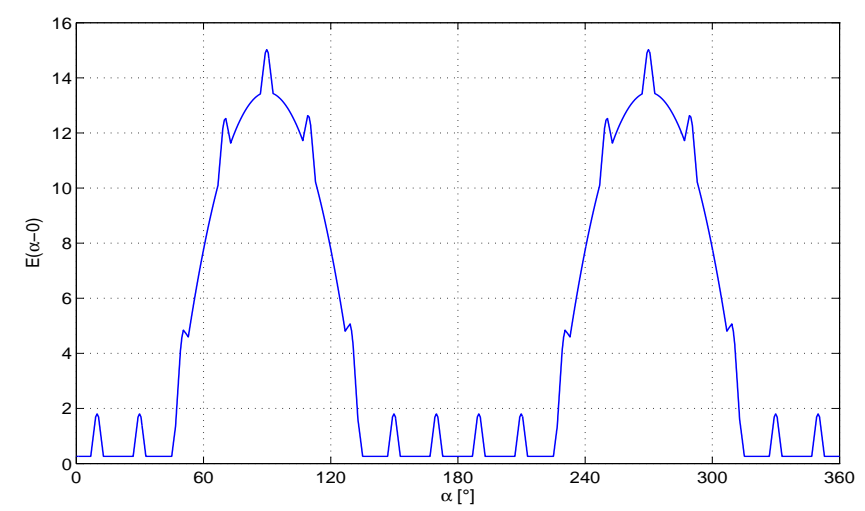

Figure 4: Total air-gap function is:

The field is invariant with respect to $z$ axis (perpendicular axis to the cross section of figure 1 ). The volume element

$$
d v=R L e(\alpha-\theta) d \alpha
$$

(5) is then transformed to:

$$
W(\theta)=\frac{\mu_{0} R L}{2} \int_{0}^{2 \pi} e(\alpha-\theta) H^{2}(\alpha-\theta) d \alpha .
$$

Considering that the three phases $a, b$ and $c$ are fed by three-phase balanced currents synchronized with the rotor position. By replacing (1) in (7), we obtain:

$$
W(\theta)=\frac{\mu_{0} R L}{2} \int_{0}^{2 \pi} \frac{1}{e(\alpha-\theta)}\left(N_{a}(\alpha) i_{a}(\theta)+N_{b}(\alpha) i_{b}(\theta)+N_{c}(\alpha) i_{c}(\theta)\right)^{2} d \alpha .
$$

The development of (8) gives:

$$
\begin{aligned}
W(\theta) & =\frac{\mu_{0} R L}{2} \sum_{i=a, b, c} \int_{0}^{2 \pi} \frac{1}{e(\alpha-\theta)} N_{i}^{2}(\alpha) i_{i}^{2}(\theta) d \alpha \\
& +\frac{\mu_{0} R L}{2} \sum_{i=a, b, c} \sum_{j=a, b, c} \int_{0}^{2 \pi} \frac{1}{e(\alpha-\theta)} N_{i}(\alpha) N_{j}(\alpha) i_{i}(\theta) i_{j}(\theta) d \alpha .
\end{aligned}
$$

In other hand, we know the energy expression of a magnetically coupled circuit in terms of inductances and currents as [7]:

$$
W(\theta)=\sum_{i=a, b, c} \frac{1}{2} L_{i}(\theta) i_{i}^{2}(\theta)+\sum_{i=a, b, c} \sum_{j=a, b, c} \frac{1}{2} M_{i j}(\theta) i_{i}(\theta) i_{j}(\theta)
$$

with $L_{i}(\theta)$ is the self inductance of the phase $i$ and $M_{i j}(\theta)$ the mutual inductance between the phase $i$ and the phase $j$.

Equaling (9) and (10), we obtain the general expressions of the self and mutual inductances:

$$
L_{i}(\theta)=\mu_{0} R L \int_{0}^{2 \pi} \frac{1}{e(\alpha-\theta)} N_{i}^{2}(\alpha) d \alpha
$$




$$
M_{i j}(\theta)=\mu_{0} R L \int_{0}^{2 \pi} \frac{1}{e(\alpha-\theta)} N_{i}(\alpha) N_{j}(\alpha) d \alpha .
$$

\subsection{Torque computation}

The machine electromagnetic torque $\Gamma_{e m}$ is obtained from the magnetic co-energy $W_{c o}$ :

$$
\Gamma_{e m}(\theta)=p\left[\frac{\partial W_{c o}}{\partial \theta}\right]_{(\text {I constant })}
$$

where $p$ is pole pairs number.

In a linear magnetic system, the co-energy is equal to the stored energy:

$$
W_{c o}=\frac{1}{2} p[I(\theta)]^{t}[L(\theta)][I(\theta)]
$$

where $L(\theta)$ is the inductance matrix:

$$
L(\theta)=\left[\begin{array}{ccc}
L_{a}(\theta) & M_{a b}(\theta) & M_{a c}(\theta) \\
M_{a b}(\theta) & L_{b}(\theta) & M_{b c}(\theta) \\
M_{a c}(\theta) & M_{b c}(\theta) & L_{c}(\theta)
\end{array}\right]
$$

The electromagnetic torque is then:

$$
\Gamma_{e m}(\theta)=\frac{1}{2} p[I]^{t}\left[\frac{\partial L}{\partial \theta}\right][I]
$$

In the case of sinusoidal excitation the currents vector is:

$$
[I(\theta)]=\left[\begin{array}{c}
\sqrt{2} I_{r m s} \cos (\theta+\psi) \\
\sqrt{2} I_{r m s} \cos \left(\theta-\frac{2 \pi}{3}+\psi\right) \\
\sqrt{2} I_{r m s} \cos \left(\theta+\frac{2 \pi}{3}+\psi\right)
\end{array}\right]
$$

with $\psi$ the load angle, the choice of $\psi=45^{\circ}$ maximize the mean value of electromagnetic torque.

\subsection{Application}

A detailed comparison of the presented method with the finite elements method is done in [9] where quasi similar results of the two methods are shown.

Here, the method is applied to a SynRM those parameters are given in table 1. Figure 5 shows the obtained inductances and electromagnetic torque using respectively (11), (12) and (16). One can observe torque pulsations while the machine is optimized for low torque ripple purpose [4]. Despite that the machine is skewed, residual torque pulsations caused by windings distribution and rotor saliency are important (around $26 \%$ of the mean value). These undulations can not be attenuated by structure optimization. The idea to outperform this problem consists on feeding the machine by suitable currents waveshapes, that is the object of the next section. 
Table 1: Dimensions of the machine

\begin{tabular}{|c|c|c|}
\hline \hline Symbol & Quantity & Value \\
\hline $\mathrm{p}$ & Number of pole pairs & 2 \\
$\mathrm{R}$ & Rotor outer radius & $45 \mathrm{~mm}$ \\
$\mathrm{e} 1$ & Air-gap length & $0.26 \mathrm{~mm}$ \\
$\mathrm{~N}$ & Number of turns in series per phase & 29 \\
$\mathrm{Ne}$ & Number of stator slots & 36 \\
$\mathrm{~L}$ & Active axial length & $155 \mathrm{~mm}$ \\
$\beta$ & Pole arc & $45^{\circ}$ \\
$\mathrm{e} 2$ & Interpolar air-gap length & $10 \mathrm{~mm}$ \\
$\delta$ & Skewing angle & $10^{\circ}$ \\
$\mathrm{k}$ & Chording factor & 1 (no chording) \\
\hline \hline
\end{tabular}
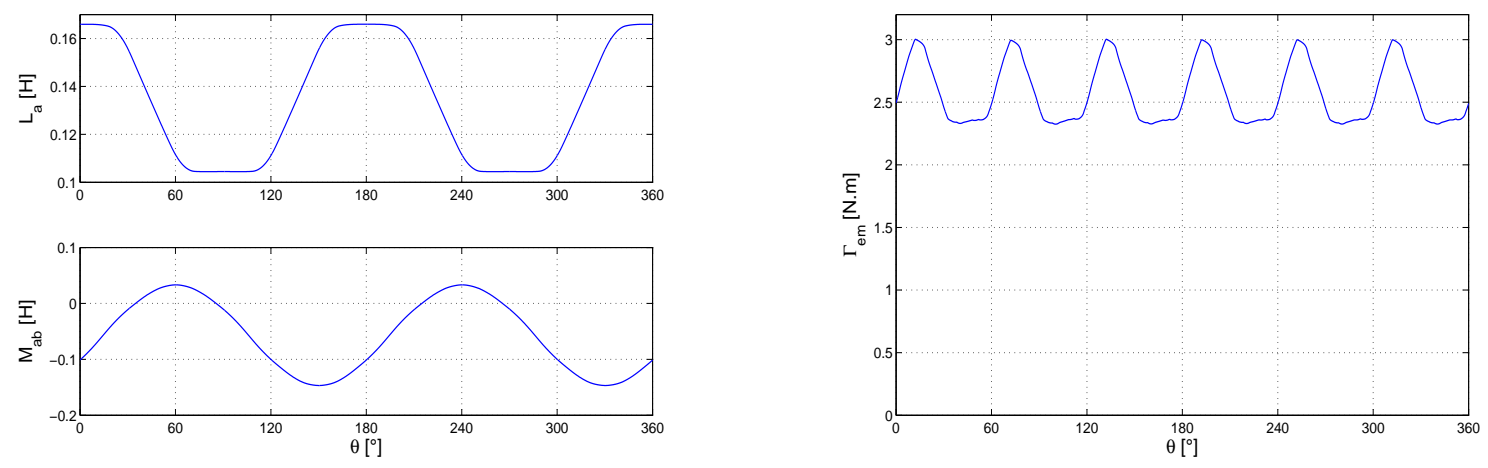

(a) Self and mutual inductances

(b) Electromagnetic torque

Figure 5: Computed inductances and electromagnetic torque

\section{Optimal currents for torque ripple cancellation}

Using Park's transformation [15] and neglecting the homopolar current (3-wires star connexion for the stator windings), we have:

$$
\left[\begin{array}{c}
i_{d} \\
i_{q}
\end{array}\right]=[P]\left[\begin{array}{c}
i_{a} \\
i_{b} \\
i_{c}
\end{array}\right]
$$

where $i_{d}(\theta)$ and $i_{q}(\theta)$ are the $d$ and $q$ current components. The Park transform is defined as:

$$
[P]=\sqrt{\frac{2}{3}}\left[\begin{array}{ccc}
\cos (\theta) & \cos \left(\theta-\frac{2 \pi}{3}\right) & \cos \left(\theta+\frac{2 \pi}{3}\right) \\
\sin (\theta) & \sin \left(\theta-\frac{2 \pi}{3}\right) & \sin \left(\theta+\frac{2 \pi}{3}\right)
\end{array}\right]
$$

with $[P]^{-1}=[P]^{t}$.

The expression (16) is then transformed to:

$$
\Gamma_{e m}(\theta)=\frac{1}{2} p\left[\begin{array}{c}
i_{d}(\theta) \\
i_{q}(\theta)
\end{array}\right]^{t}\left[\begin{array}{ll}
L_{d d \gamma}(\theta) & L_{d q \gamma}(\theta) \\
L_{d q \gamma}(\theta) & L_{q q \gamma}(\theta)
\end{array}\right]\left[\begin{array}{c}
i_{d}(\theta) \\
i_{q}(\theta)
\end{array}\right]
$$

$L_{d d \gamma}, L_{q q \gamma}$ and $L_{d q \gamma}$ are obtained by Park transformation of derivative inductances matrix:

$$
\left[\begin{array}{ll}
L_{d d \gamma}(\theta) & L_{d q \gamma}(\theta) \\
L_{d q \gamma}(\theta) & L_{q q \gamma}(\theta)
\end{array}\right]=[P]^{t}\left[\frac{\partial L}{\partial \theta}\right][P]
$$


The development of (20) gives:

$$
\Gamma_{e m}(\theta)=A(\theta) i_{d}^{2}(\theta)+B(\theta) i_{q}^{2}(\theta)+C(\theta) i_{d}(\theta) i_{q}(\theta)
$$

with:

$$
\begin{aligned}
& A(\theta)=L_{d d \gamma}(\theta)+L_{d q \gamma}(\theta) \\
& B(\theta)=L_{q q \gamma}(\theta)+L_{d q \gamma}(\theta) \\
& C(\theta)=L_{d d \gamma}(\theta)+L_{q q \gamma}(\theta)+2 L_{d q \gamma}(\theta)
\end{aligned}
$$

In order to have the maximum torque for minimum Joule losses, we must impose $i_{d}(\theta)=i_{q}(\theta)=I_{\text {ref }}(\theta)$. Equaling $\Gamma_{e m}(\theta)$ to the desired torque reference $\Gamma_{d}$ for each rotor position, we obtain the optimal current:

$$
I_{\text {opt }}(\theta)=\sqrt{\frac{\Gamma_{d}}{A(\theta)+B(\theta)+C(\theta)}} .
$$

In the case of speed control, it is preferable to fix $i_{d}$ on its nominal value $I_{d r e f}$ avoiding strong saturation [1]. For each rotor position, to obtain the optimal $q$ axis current $i_{q o p t}$, we search the adequate root of the second degree polynomial :

$$
B(\theta) i_{q}^{2}(\theta)+C(\theta) I_{d r e f} i_{q}(\theta)+A(\theta) I_{d r e f}^{2}-\Gamma_{d}=0
$$

Figure ?? shows the electromagnetic torque obtained with and without optimal currents injection. The optimal current computed by (24) is shown in figure 6a. We can observe that torque pulsations are totally canceled.

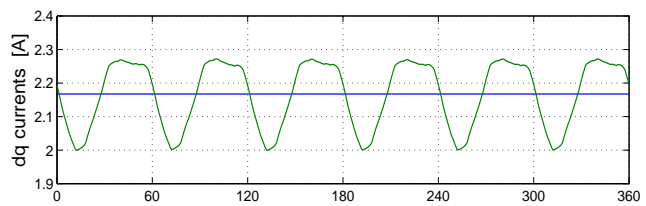

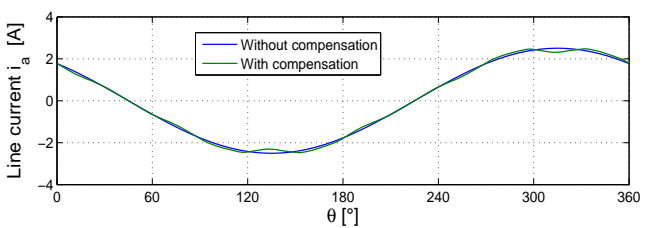

(a) Feeding currents

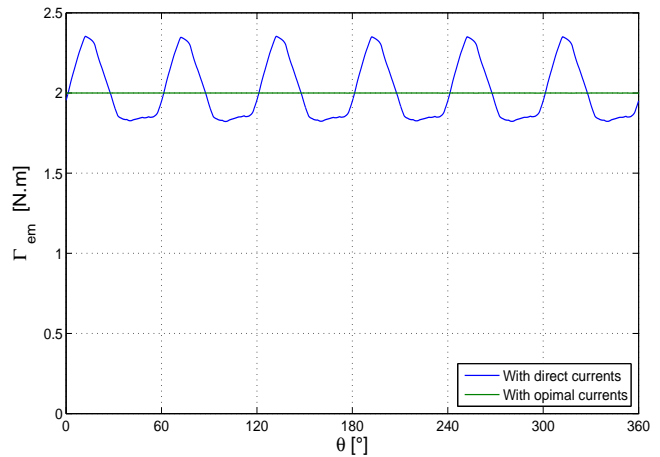

(b) Electromagnetic torque

Figure 6: Comparison of steady-state results in two cases: with and without optimal current

\subsection{Vector control with optimal currents}

The synoptic scheme of the vector control of SynRM with optimal currents injection and without speed regulation is shown in figure 7. Starting from a desired value of torque, the calculated currents are tracked by PI controllers. The simulated machine is whose described previously. The parameters used for dynamic simulations are the viscous friction $K_{f}=0.0018 \mathrm{~m}^{-1} \cdot \mathrm{s}^{-1}$, the moment of inertia $J=0.037 \mathrm{~kg} \cdot \mathrm{m}^{2}$ and a resistance of one stator phase $R_{s}=2 \Omega$. The simulations are done using Matlab/Simulink software.

Figure 8 chows the dynamic behavior of dq currents and the resulting torque in the case of no torque ripple compensation. We can observe the torque undulations, the increasing frequency is due to the fact that the speed does not achieve the steady-state because no speed regulation is performed. In the case of optimal currents injection (figure 9), at low speed the torque is no ripple containing because the optimal currents are well tracked by the controllers. However, when the speed increases some undulations of the torque are remarquable because of the limited capability of the controllers to track high frequency signals. Indeed, the bandwidth of a controller is limited by the stability condition of the closed loop dynamic system. To perform high frequency signal tracking one must perform an other controller such as hysteresis controller for example. 


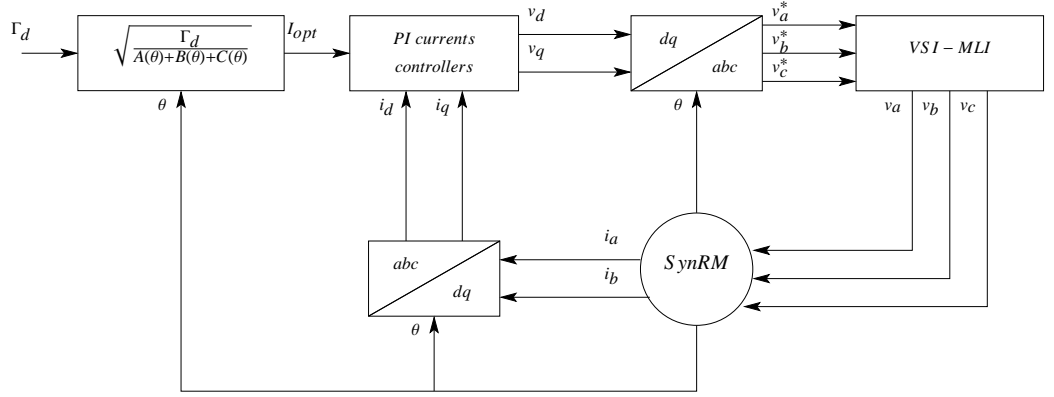

Figure 7: Synoptic scheme of current vector control with optimal currents injection

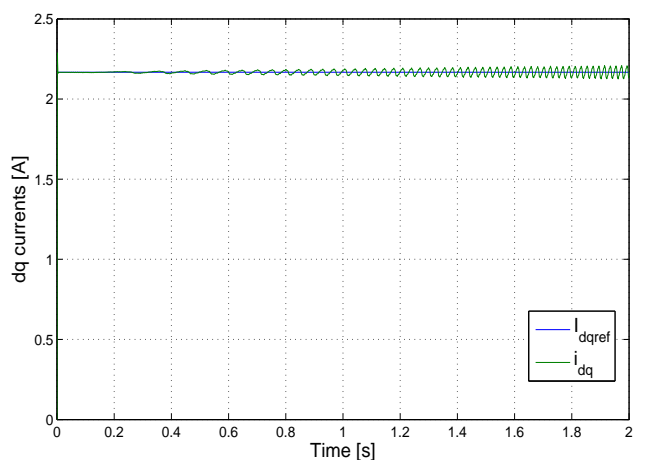

(a) Reference and regulated dq currents

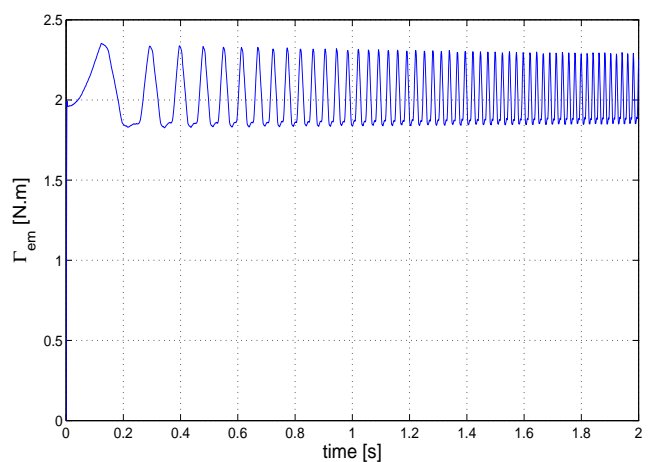

(b) Electromagnetic torque

Figure 8: Dynamic simulation of current vector control without optimal currents injection

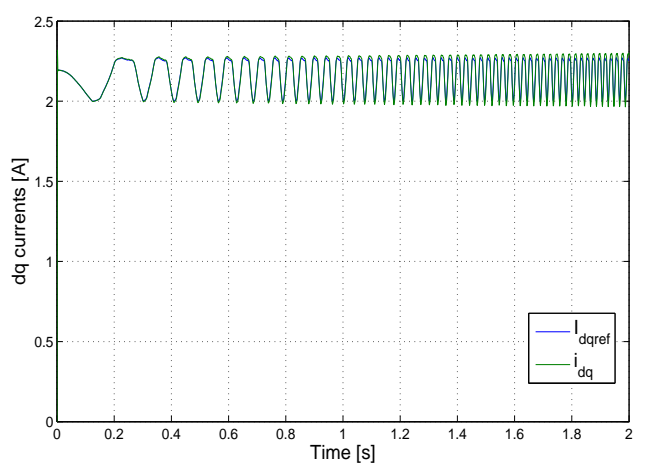

(a) Reference and regulated dq currents

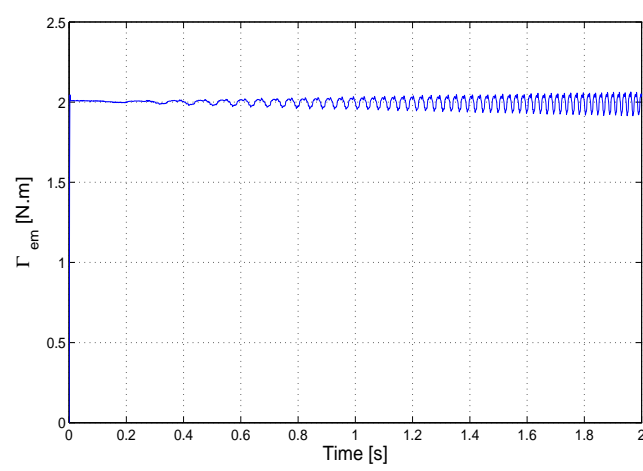

(b) Electromagnetic torque

Figure 9: Dynamic simulation of current vector control with optimal currents injection

In the case of speed vector control (figure 10), the reference torque value is determined by the speed controller. The optimal current $I_{q o p t}$ is obtained by solving the equation (25) while the reference of d-axis current $I_{\text {dref }}$ is maintained constant. The obtained results for a reference speed of $10 \mathrm{rad} / \mathrm{s}$ are shown in figure 11 . We can observe that quasi total ripple cancellation is achieved and the velocity is smooth at steady-state. However, a relatively high overshoot on the speed response is remarquable. 


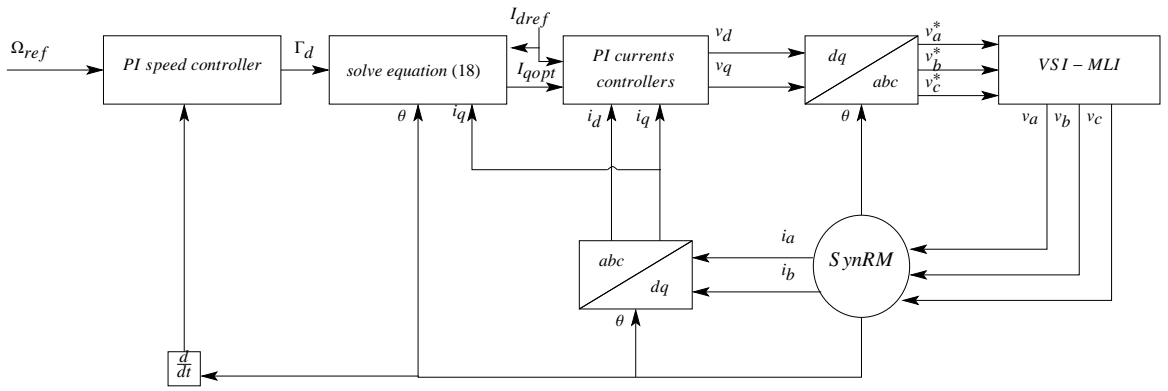

Figure 10: Synoptic scheme of speed vector control with optimal currents injection

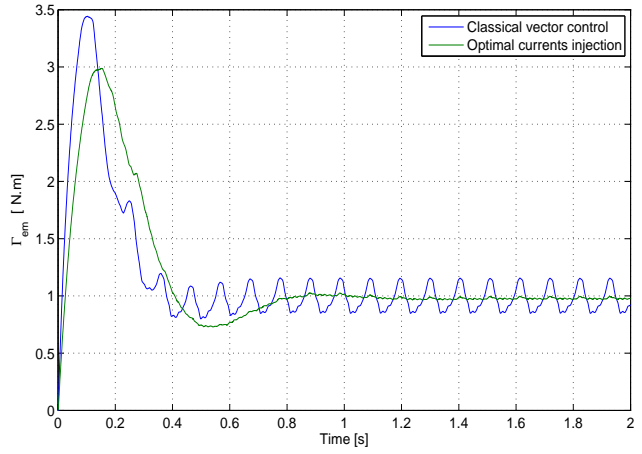

(a) Electromagnetic torque

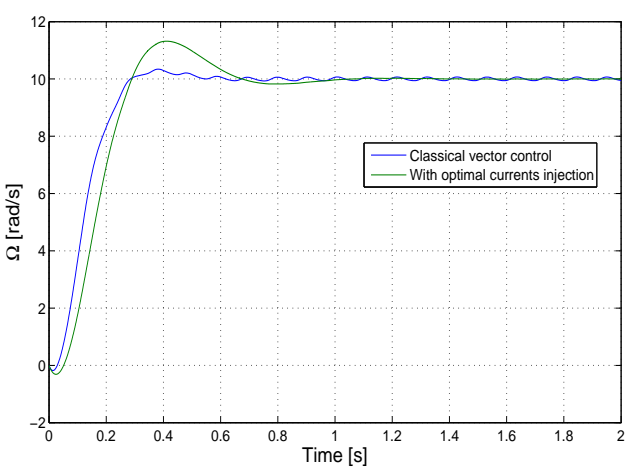

(b) Speed

Figure 11: Dynamic simulation of speed vector control with and without optimal currents injection

\section{Experimental implementation of the off-line currents predetermination method}

The experimental prototype SynRM is manufactured by milling a standard 4-pole, $3 \mathrm{~kW}$ squirrel cage induction motor. The stator of the considered motor contains 36 slots with three phase full pitch winding $\left(k=\frac{9}{9}\right)$. The skewing angle of the rotor bars being equal to $13^{\circ}$ determines the direction of milling to obtain the rotor salient poles. The manufactured rotor is shown in figure 12. It has the following parameters : $\beta=45^{\circ}, e 2=10 \mathrm{~mm}$ and $\delta=13^{\circ}$. To avoid damping effect, the rotor end-rings are cut-off. A VSI inverter drives the SynRM by imposing the reference voltages calculated by the controllers using PWM technique. A DSP card (dSPACE 1102) is used for numerical implementation of control algorithms. A de machine is coupled to the SynRM working as a variable load.

Figures 14a and 14b show the computed and measured self and mutual inductances. The measurement test is done at stand-still. The rotor being blocked on a desired position $\theta$, one stator phase is fed by a step voltage of low amplitude to avoid saturation effect (fig. 13). The task is done for $\theta$ varying from 0 to $90^{\circ}$ with an increment of $1^{\circ}$. The inductances are obtained as follow:

$$
\begin{aligned}
& L_{a}(\theta)=\frac{\psi_{a \infty}}{i_{a \infty}}=\frac{\int_{0}^{t_{\infty}}\left(v_{a}(t)-R_{s} i_{a}(t)\right) d t}{i_{a \infty}} \\
& M_{a b}(\theta)=\frac{\psi_{a b \infty}}{i_{a \infty}}=\frac{\int_{0}^{t_{\infty}} v_{b}(t) d t}{i_{a \infty}}
\end{aligned}
$$

where $L_{a}$ and $M_{a b}$ are the self and mutual inductances, $\psi_{a \infty}$ and $\psi_{a b \infty}$ the steady-state flux of phases $a$ and $b, v_{a}(t)$ and $v_{b}(t)$ are the excitation voltage of phase $a$ and the induced one in phase $b, i_{a}$ and $i_{a \infty}$ are the instantaneous and the steady-state current of phase $a$. 


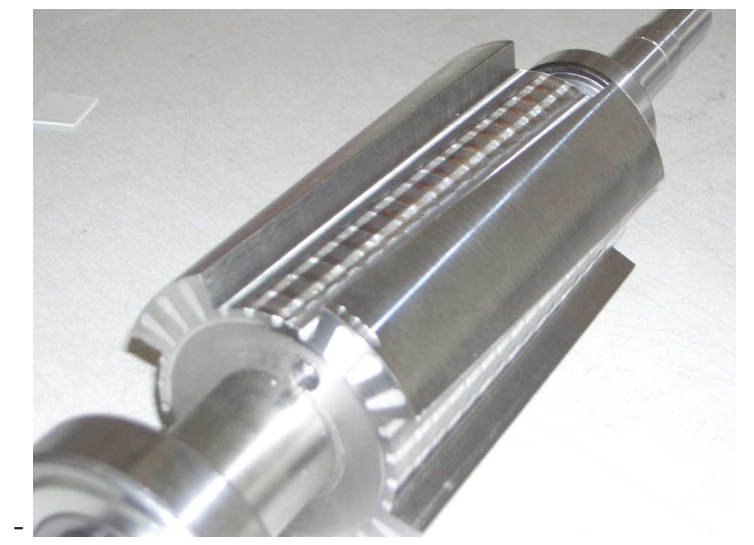

(a) Photography

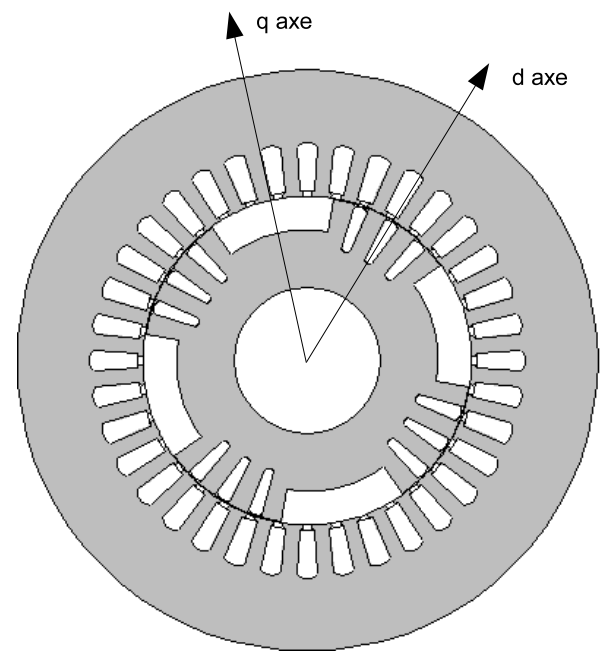

(b) Cross section

Figure 12: Manufactured rotor

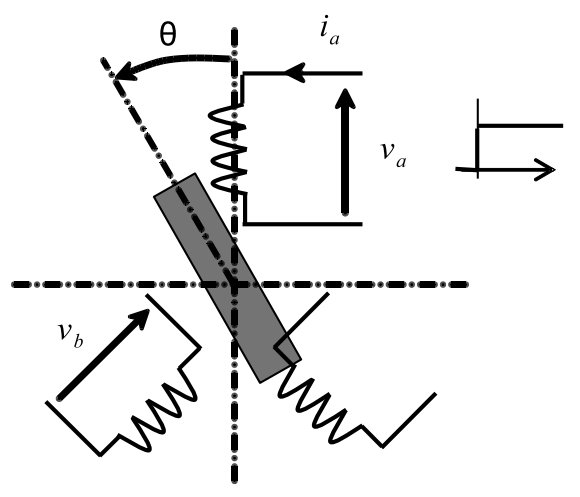

Figure 13: Self and Mutual inductances measurement test

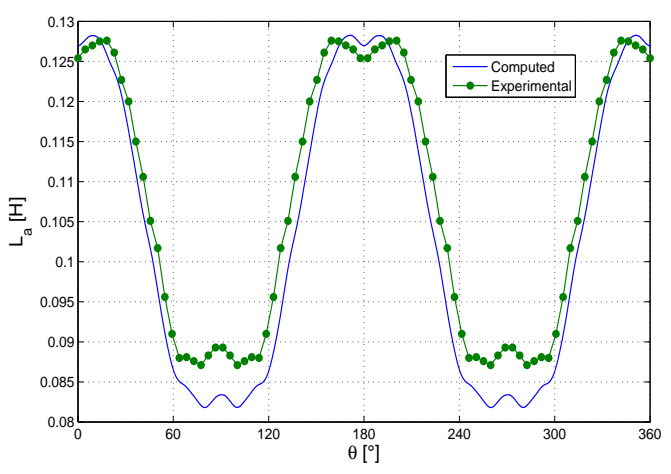

(a) Self inductance versus Electrical Angle

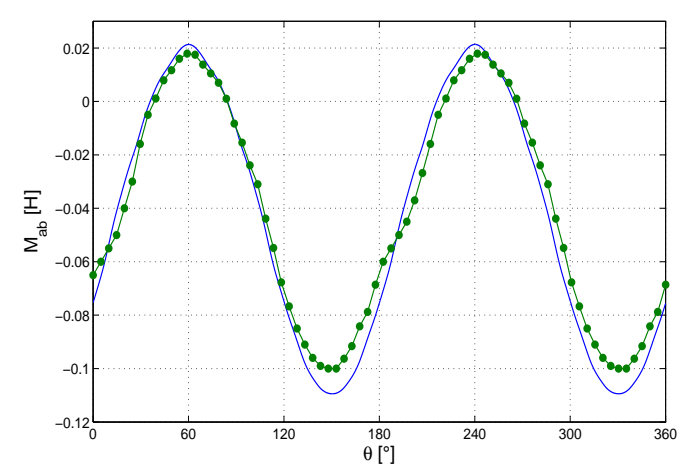

(b) Mutual inductance versus Electrical Angle

Figure 14: Experimental and computed inductances 
Significant harmonics of inductances are given in tables 2 and 3. One can observe the good agreement between the computed and measured inductances

Table 2: Self inductance harmonics

\begin{tabular}{|c|c|c|}
\hline \hline Harmonic order & winding function method & experimental result \\
\hline dc-value & 0.1036 & 0.1075 \\
\hline$L_{2}$ & 0.0255 & 0.0225 \\
\hline$L_{4}$ & 0.0020 & 0.0012 \\
\hline$L_{6}$ & -0.0028 & -0.0039 \\
\hline \hline
\end{tabular}

Table 3: Mutual inductance harmonics

\begin{tabular}{|c|c|c|}
\hline \hline Harmonic order & winding function method & experimental result \\
\hline dc-value & -0.0432 & -0.0410 \\
\hline$M_{2}$ & 0.0647 & 0.0537 \\
\hline$M_{4}$ & -0.0017 & -0.0012 \\
\hline$M_{6}$ & $1.51 E^{-05}$ & 0.0029 \\
\hline
\end{tabular}

Figure 15 shows the optimal current and the corresponding torque for a reference torque value of $2 N . m$. The optimal current is obtained like for the machine without slots in the rotor (equation (24)). Rotor slots are taken for account in the inductances computation by adding an other air-gap function traducing this phenomenon.

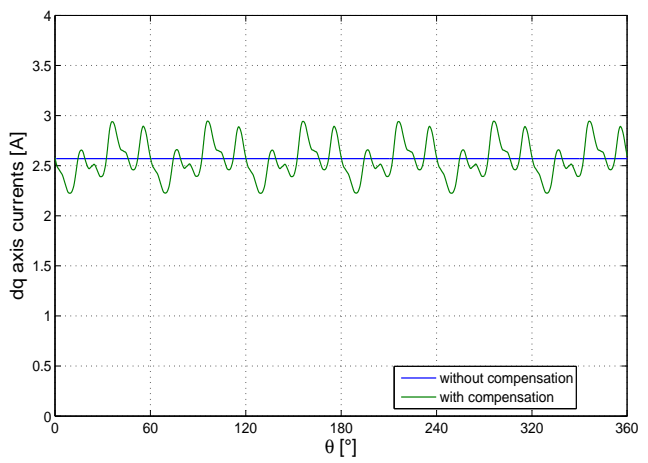

(a) feeding currents

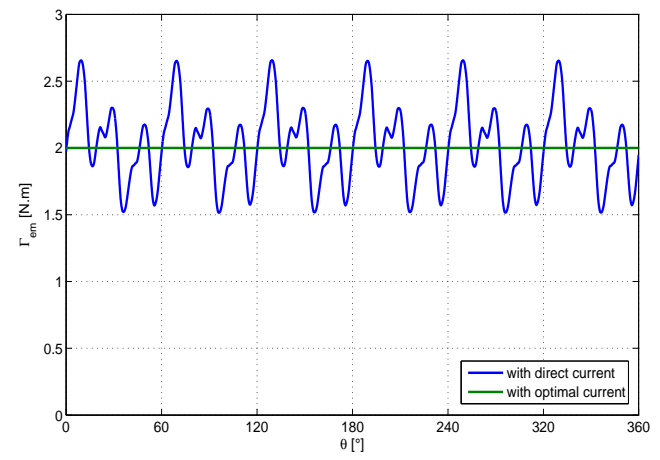

(b) Electromagnetic torque

Figure 15: Optimal dq currents and the corresponding torque

The electromagnetic torque is estimated by:

$$
\Gamma_{e m}(t)=\frac{e_{a}(t) i_{a}(t)+e_{b}(t) i_{b}(t)+e_{c}(t) i_{c}(t)}{\Omega}
$$

with:

$$
e_{i}(t)=v_{\text {iref }}(t)-R_{s} i_{i}(t) \quad, i=a, b, c
$$

where $v_{\text {iref }}(t)$ and $i_{i}(t)$ are respectively the reference voltage and the line current of phase $\mathrm{i}$ and $\Omega$ is the mechanical speed. 
From expression (29) one can deduce the inconvenience to estimate the electromagnetic torque at low speed. As explained in [5], the voltage drop caused by IGBTs dead time is not negligible at low speed. Indeed, the real mean value voltage supplying the machine windings is:

$$
\left\langle v_{i}\right\rangle=\left\langle v_{\text {iref }}\right\rangle-\Delta v
$$

with:

$$
\Delta v=\frac{t_{d} V_{d c}}{T_{P W M}}
$$

where $t_{d}$ is the dead time of the inverter, $T_{P W M}$ the pulse width modulation period $T_{P W M}=100 \mu$ sand the voltage level of the dc bus $V_{d c}=500 \mathrm{~V}$. A value of $3.8 \mu \mathrm{s}$ to $t_{d}$ is measured in our inverter making $\Delta v=19 \mathrm{~V}$. Experimental tests have shown that for $\Omega>125 \mathrm{rad} / \mathrm{s}$ the voltage drop $\Delta v$ is negligible. Hence to estimate correctly the electromagnetic torque, all measurements have been done for $\Omega>125 \mathrm{rad} / \mathrm{s}$.

Because of the imposed high fundamental frequency explained below, the current controllers can not track the higher harmonics above the sixth. Hence, we have limited our study to only the sixth current harmonic injection. Hence, the injected current is:

$$
I_{\text {opt }}(\theta)=M+H_{6} \sin 6 \theta
$$

with $\Gamma_{d}=2 N . m$ and the values of inductances harmonics given in tables 2 and 3 , we obtain:

$$
I_{o p t}(\theta)=2.54-0.13 \sin 6 \theta
$$

Figures $16 \mathrm{a}$ and $16 \mathrm{~b}$ represent respectively the estimated electromagnetic torque and its Fourier expansion with and without sixth current harmonic injection. We can observe a reduction of torque harmonic magnitude essentially the sixth. However, we constate a slight increase of the twelfth torque harmonic.

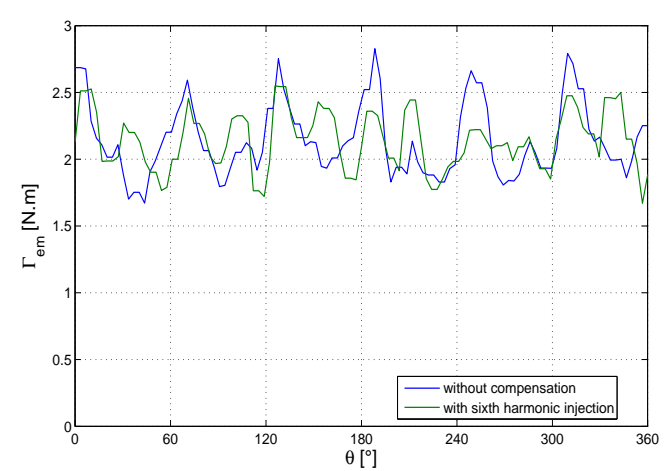

(a) Electromagnetic torque

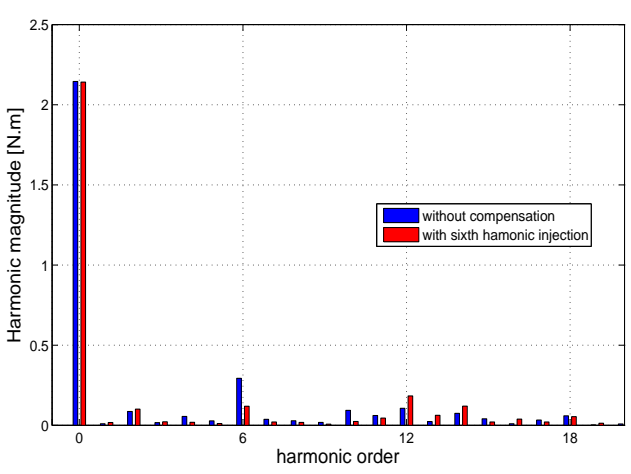

(b) Fourier expansion

Figure 16: Estimated torque and its Fourier expansion with and without sixth current harmonic injection

To confirm this result, a sweeping on the magnitude of the sixth current harmonic $H_{6}$ from $-0.2 A$ to $0.05 A$ is done and the evolution of the sixth torque harmonic is plotted on figure 17. The same optimum value is obtained for both theoretical and experimental cases while an error on magnitude can be observed, this is probably due to an error in torque estimation and poor tracking performance of PI controllers.

\section{Conclusion}

An efficient and simple method for torque ripple minimization in a synchronous reluctance motor is developed. The proposed model is based on winding function approach, it allows accounting for all space harmonics, then the 


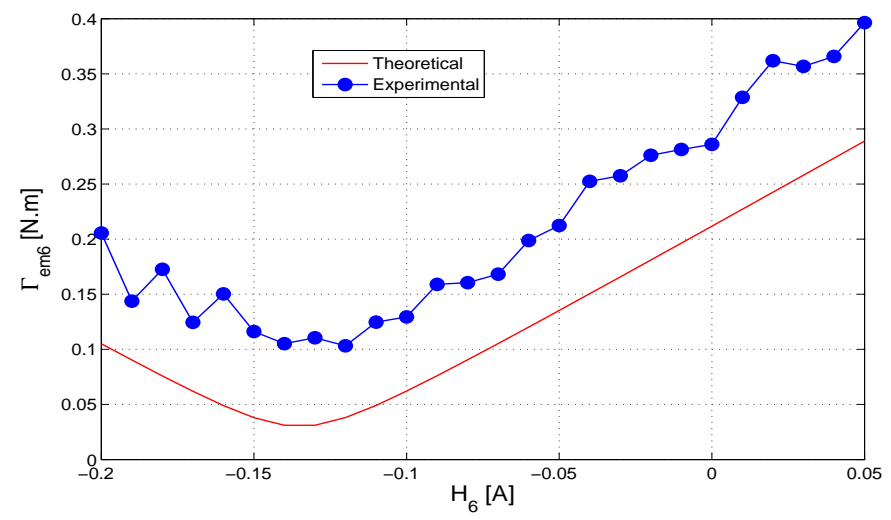

Figure 17: Sixth electromagnetic torque harmonic versus the sixth current harmonic: theoretical and experimental result

whole spectrum of electromagnetic torque is accessible. Furthermore, the computing time is strongly minimized compared to other methods based on numerical resolution of field equations.

Theoretically, the electromagnetic torque can be maintained constant by the injection of the optimal computed current waveshapes. Because of difficulty to estimate electromagnetic torque at low speed, experimental verification of the method was done at high speed where the injected optimal current harmonics can not be tracked by current controllers. Hence, we have limited our experimental study to only the sixth current harmonic and satisfactory results have been obtained showing a significant attenuation of the sixth torque harmonic. Future work consists to validate our method at low speed were speed harmonics are noteworthy. In this case, load current regulation is mandatory to maintain a constant load torque. Also, online autocompensation observer/estimator-based technique is under experimentation.

\section{References}

[1] I. Boldea, Reluctance Synchronous Machines and Drives, Clarendon Press-Oxford, 1996, 224p.

[2] A. Chiba, F. Nakamura, T. Kukao, and M. A. Rahman, Inductances of Cageless Reluctance-Synchronous Machines Having Non-sinusoidal Space Distributions, IEEE Trans. Industry Applications, vol. 27, No. 1, pp. 44-51, 1991

[3] S. Clenet, Y. Lefèvre, N. Sadowski, S. Astier and M. Lajoie-Mazenc, Compensation of Permanent Magnet Motors Torque Ripple by Means of Current Supply Waveshapes Control Determined by Finite Element Method, IEEE Trans. Mag., Vol. 29, No. 2, March 1993, pp. $2019-2023$.

[4] T. Hamiti, T. Lubin and A. Rezzoug, A simple and Efficient Tool for Design Analysis of Synchronous Reluctance Motor, Accepted for publication in IEEE Trans, August 2008.

[5] J. Holtz, Pulsewidth modulation for electronic power conversion, Proc. IEEE., Vol. 82, No. 8, August 1994, pp. $1194-1214$.

[6] Thomas M. Jahns and Wen L. Stoong, Pulsating Torque Minimization Techniques for Permanent Magnet AC Motor Drives-A Review, IEEE Transactions on Industrial Electronics, Vol. 43, No. 2, April 1996, pp. 321-330.

[7] P. C. Krause, O. Wasynczuk, and S. D. Sudhoff, Analysis of Electric Machinery, Piscataway, NJ: IEEE Press, 1995.

[8] J. H. Lee, Efficiency evaluation of synchronous reluctance motor using FEM and Preisach modeling, IEEE Trans. Mag., vol. 39, pp. 32713273, Sept. 2003

[9] T. Lubin, T. Hamiti, H. Razik and A. Rezzoug, Comparison between Finite Element Analysis and Winding Function Theory for Inductances and Torque Calculation of a SynRM, IEEE Trans. Mag., Vol. 43, No. 8, August 2007, pp. 3406-3410.

[10] Nobuyuki Matsui, Tatsuo Makino and Hirokazu Satoh, Autocompensation of Torque Ripple of Direct Drive Motor by Torque Observer , IEEE Trans. Ind. Applicat., Vol. 29, No. 1, January/February 1993, pp. 187-194.

[11] P. Neti, S. Nandi, Determination of effective air-gap length of reluctance synchronous motors from experimental data, Conf. Rec. IEEE-IAS annual meeting, pp. 86-93, 2004.

[12] I. Tabatabei, J. Faiz, H. Lesani and M. T. Nabavi-Razavi, Modeling and simulation of a salient-pole synchronous generator with dynamic eccentricity using modified winding function theory, IEEE Trans. Mag., vol. 40, pp. 1550-1555, May 2004.

[13] X. Tu, L.-A. Dessaint, M. El Kahel, A.Barry, Modeling and experimental validation of internal faults in salient pole synchronous machines including space harmonics, Mathematics and Computers in Simulation, vol. 71, pp. 425-439, 2006.

[14] A. Vagati, A. Canova, M. Chiampi, M. Pastorelli and M. Repetto, Design refinement of synchronous reluctance motor through finite element analysis, IEEE Trans. Industry Applications, vol. 36, No. 4, pp. 1094-1102, 2000.

[15] P. Vas, Electrical Machines and Drives: A Space-Vector Theory Approach, Oxford University Press, 1993, 832p. 